\title{
Rare case of huge rectal and uterovaginal prolapse
}

\author{
Manisha M. Laddad ${ }^{1}$, Nitin S. Kshirsagar ${ }^{1}$, Nitin Nagre ${ }^{2}$
}

${ }^{1}$ Department of Obstetrics \& Gynecology, Krishna Institute of Medical Sciences, Karad, Maharashtra, India
${ }^{2}$ Department of Surgery, Krishna Institute of Medical Sciences, Karad, Maharashtra, India

Received: 31 March 2013

Accepted: 14 April 2013

\section{*Correspondence:}

Dr. Manisha M. Laddad,

E-mail: drmanishald@gmail.com

(C) 2013 Laddad MM et al. This is an open-access article distributed under the terms of the Creative Commons Attribution License, which permits unrestricted use, distribution, and reproduction in any medium, provided the original work is properly cited.

\begin{abstract}
A case of combined genital prolapse and rectal prolapse in a 60-year-old multipara is reported. The treatment of mixed prolapse remains surgical and should be treated the genital prolapse by vaginal hysterectomy with pelvic floor repair and the rectal prolapse by means of the Delorme operation. The mortality and morbidity rates are zero if this operation is used and the relapse rate is only 8 to $11 \%$ for the rectal prolapse. It would appear that the two approaches are rarely associated by the authors and would seem to be interesting to reconsider this question by indicating mixed treatment of the two prolapses whenever possible.
\end{abstract}

Keywords: Rectal prolapse, uterine prolapse, vaginal hysterectomy, Delorme operation

\section{INTRODUCTION}

Concurrent occurrence of rectal and uterovaginal prolapse in many women living in the community should be made aware that there is possible solution to this dual debilitating condition by surgical correction which can be acquired at the same sitting to bring changes in their quality of life. Rectal prolapse and uterovaginal prolapse has been described at all ages. Peaks of incidence are observed in the fourth and seventh decades of life.

\section{CASE REPORT}

A 60 years old multipara admitted at Krishna Institute of Medical Sciences on 12/01/2013 with c/o something coming out of vagina since one year, foul smelling discharge since two months and constipation on and off and something coming out through rectum since one month. Patient was multiparous gravida 6 , para 6 with all full term normal deliveries at home. She had no major medical illness or surgery in past. On general examination vitals were stable. On per abdominal examination abdomen was soft, on local examination there was huge foul smelling third degree uterine prolapse with decubitus ulcer, with cystocele, rectocele and enterocele, and there was huge thick rectal prolapse 6 to $7 \mathrm{~cm}$ seen. On $\mathrm{p} / \mathrm{v}$ examination uterus was atrophic, uterocervical length was 7 inches. So final diagnosis was made postmenopausal multiparous women with huge uterine and rectal prolapse.

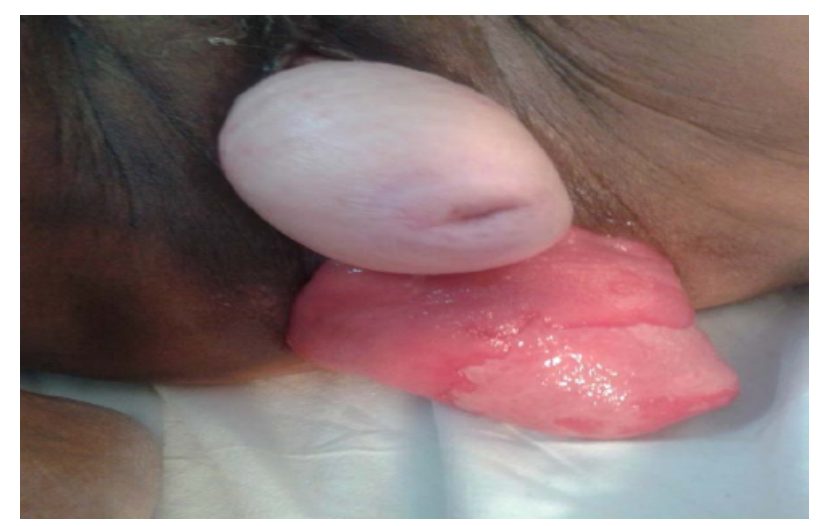

Figure 1: Preoperative picture. 


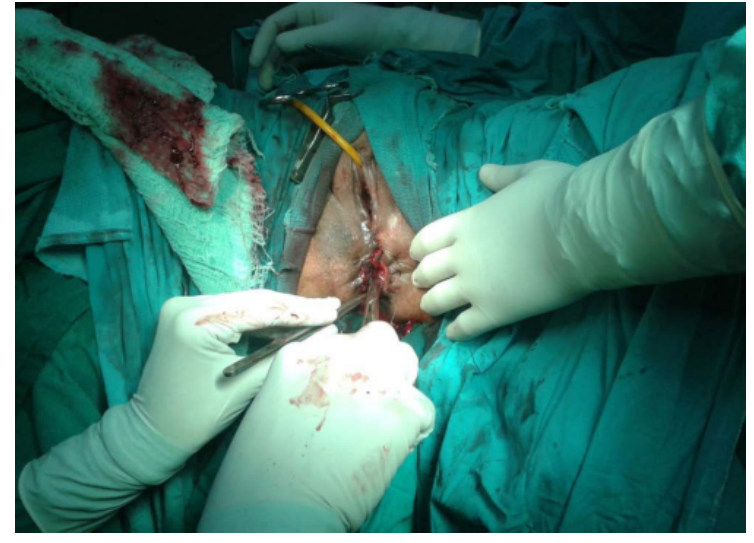

Figure 2: Postoperative picture after vaginal hysterectomy with pelvic floor repair and repair of rectal prolapse by Delorme method.

Patient was admitted and investigated, all blood reports were normal. Vaginal packing and rectal packing was done with Betadine, glycerin and acriflavine. after one week she was operated for surgery under epidural anaesthesia for vaginal hysterectomy with pelvic floor repair done by us and rectal prolapse was operated by surgeon by Delorme method by Tran's perineal approach. Post operative period was uneventful. Patient was discharged on seventh post operative day without any complication.

\section{Histopathology report}

Gross: Atrophic uterus with cervical elongation m. $12 \times 3 \times 5 \mathrm{~cm}$.

Microscopically: Suggestive of atrophic endometrium with nonspecific changes, with chronic cervicitis.

\section{DISCUSSION}

The incidence of prolapse increases according to age. It is a common gynaecology problem in postmenopausal women. Rarely uterine prolapse can be manifested along with rectal prolapse. ${ }^{2,7,8}$

Prolapse refers to "the falling down or slipping of a body part from its usual position or relations". It is derived from the Latin pro- - "forward" + labi - "to slide". Pelvic relaxation is a weakness or laxity in the supporting structures of the pelvic region. Bladder, rectal, or uterine tissue may then bulge into the vagina. This is called pelvic organ prolapse.

Rectal prolapse is a condition in which part of the wall or the entire wall of the rectum falls out of place.

\section{Causes of pelvic organ and rectal prolapse}

Uterine prolapse (or Pelvic organ prolapse) occurs when the female pelvic organs fall from their normal position, into or through the vagina. Occurring in women of all ages, it is more common as women age, particularly in those who have delivered large babies or had exceedingly long pushing phases of labor. Smoking, obesity, connective tissue disorders, upper respiratory disorders, and repetitive strain injuries can all increase prolapse risk

Pelvic support comes from pelvic floor muscles, connecting tissue (fascia), and thickened pieces of fascia that serve as ligaments. When pelvic floor muscles are weakened, the fascia and ligaments have to bear the brunt of the weight. Eventually, they may stretch and fail, allowing pelvic organs to drop and press into the vaginal wall.

Women who have had multiple vaginal births are at greatest risk for pelvic organ prolapse, particularly after menopause. ${ }^{1,3,8}$ Other risk factors include surgery to the pelvic floor, connective tissue disorders, and obesity.

Symptoms of pelvic organ prolapse: Women with mild prolapse discovered during a routine pelvic exam may have no symptoms at all. But others experience considerable discomfort and a range of symptoms, including:

Pressure and pain: The most common complaints are a feeling of pelvic pressure, or bearing down, leg fatigue, and low back pain.

Urinary symptoms: Cystocele, urethrocele, and uterine prolapse can cause stress incontinence and difficulty in starting to urinate.

Bowel symptoms: A rectocele may cause problems with defecation by forming a pocket just above the anal sphincter. Stool can become trapped, causing pain, pressure, and constipation.

Sexual problems: A prolapse can cause irritated vaginal tissues or pain during intercourse, as well as psychological stress.

\section{Symptoms of a rectal prolapse may be:}

- Leakage of stool

- Bleeding, anal pain, itching, irritation

- Tissue that protrudes from the rectum

\section{Treatment}

Women with no or very mild symptoms don't need treatment, although they should avoid anything that might worsen the prolapse. Losing weight if necessary, avoiding lifting heavy objects, and quitting smoking all prevent prolapses from progressing.

\section{Surgical treatment}


Before undergoing surgical repair of a prolapse, you'll need to have a thorough pelvic exam, to ensure that all problems have been identified. Be sure your surgeon has expertise in the field of pelvic reconstruction, as new procedures and anatomical knowledge have led to better results. If patient experiencing major discomfort or inconvenience, surgery is the only definitive way to relieve symptoms and improve your quality of life. ${ }^{6-8}$

\section{Surgical techniques}

Pelvic reconstruction surgery may be performed through the vaginal, transperineally or abdominally; both procedures are equally effective. A newer option is laparoscopic surgery ${ }^{5,6,8}$ the prolapsed organ will be repositioned and secured with stitches to the surrounding tissues and ligaments. The vaginal defect will be repaired, sometimes using a piece of synthetic material, called a graft. Women can usually leave the hospital within one to three days. A surgeon may operate through the abdomen to secure part of the large intestine or rectum to the inside the abdominal cavity (rectopexy). Sometimes the surgeon removes the affected part of the intestine.

Surgery also can be done through the perineum (the area between the genitals and the anus) to remove the prolapsing tissue..$^{5-7}$ Vaginal hysterectomy with pelvic floor repair, followed by repair of rectal prolapse by Delorme method is a best approach.

\section{Complications}

Possible complications of pelvic reconstructive surgery with Delorme operation include urinary tract infection, temporary or permanent incontinence, infection, bleeding, and rarely damage to the urinary tract that requires additional corrective surgery. Some women may develop chronic irritation or pain during intercourse from a suture or scar tissue. There's also a risk of recurrence, which seems to be highest for cystocele and rectal prolapse ${ }^{3-5}$ and lowest for rectocele. Fortunately, recurrence rates are dropping as surgical techniques and preoperative planning improve. The chance of recurrence will also be reduced if a woman avoids stress, such as heavy lifting or straining during a bowel movement, and performs Kegel exercises regularly before and after surgery.

\section{CONCLUSION}

Presence of uterine and rectal prolapse is rare but can be corrected in same setting by surgical approach. Postoperatively patient shows excellent result. Improvement of sphincteric tone was shown by Trans. rectal manometry, and bladder and rectal continence was maintained. The combined surgical procedure for concurrent genital and rectal prolapse is easy to perform and safe and efficient in terms of recurrence and continence. It is hoped this report will increase multidisciplinary awareness of an effective solution for a potentially debilitating problem.

Funding: None

Competing interests: None declared

Ethical approval: Not required

\section{REFERANCES}

1. Amico JC, Marino AW Jr. Prolapse of the vagina in association with rectal procidentia. Dis Colon Rectum 1968;11:115-9.

2. Campbell ZB. A report on 2,798 vaginal hysterectomies. Am J Obstet Gynecol 1946;52:598.

3. Emge LA, Durfee RB. Pelvic organ prolapse: Four thousand years of treatment. Clin Obstet Gynecol 1966;9:997.

4. Gabriel WB. The Principles and Practice of Rectal Surgery. Fifthe edition, Springfield, Ill., Charles C Thomas, 1963, pp.739.

5. Gallagher DM. Surgical management of rectal prolapse in women. Clin Obstet Gynecol 1966;9:1100-6.

6. Gray LA. Vaginal Hysterectomy; Indications, Technique, and Complications. Second edition, Springfield, Ill., Charles C. Thomas, 1963, pp.228.

7. Küpfer CA, Goligher JC. One hundred consecutive cases of complete prolapses of the rectum treated by operation. Br J Surg 1970;57:481.

8. Kriplani A, Banerjee N, Kriplani AK, Roy KK, Takkar D. Uterovaginal prolapse associated with rectal prolapse case report. Aust N Z J Obstet Gynaecol 1998;38:325-6.

DOI: $10.5455 / 2320-1770$. ijrcog20130629

Cite this article as: Laddad MM, Kshirsagar NS, Nagre N. Rare case of huge rectal and uterovaginal prolapse. Int J Reprod Contracept Obstet Gynecol 2013;2:237-9. 